\title{
SEISMIC ISOLATION OF HIGHWAY BRIDGES
}

\author{
Kazuhiko KAWASHIMA ${ }^{1}$ \\ ${ }^{1}$ Member of JAEE, Professor, Department of Civil Engineering, Tokyo Institute of Technology, \\ Tokyo, Japan, kawasima@cv.titech.ac.jp
}

\begin{abstract}
This paper introduces the seismic isolation technology for highway bridges in Japan. Systematic application of seismic isolation was initiated in early 1990s. In particular it was accelerated after the 1995 Kobe earthquake. Guidelines and design specifications for seismic isolation are introduced. Typical implementation of seismic isolation to highway bridges are also presented.
\end{abstract}

Key Words: seismic isolation, passive control, bridges, seismic design, new technical development, isolators, dampers

\section{INTRODUCTION}

Mitigation of seismic damage to structures has been a dream for structural engineers; hence a wide range of technical development has been attempted for seismic isolation from 1970s. Early implementation of the seismic isolation was underlaid by a philosophy that a technology that enabled to construct long multi-span continuous bridges, without controlled by the thermal, creep and shrinkage effects, was required. Consequently, viscous dampers were often incorporated in the 1970s Since viscous fluid with viscosity nearly free from the temperature dependence was not available at the early days, high viscosity fluid was used in the damper so that the damper resists high rate seismic movement, while it does not resist low rate movement resulting from the thermal, creep and shrinkage effects. Consequently dampers have been effectively used to distribute seismic lateral force of a superstructure to substructures, with relative displacements resulting from the thermal, creep and shrinkage effects being allowed to take place without restriction. This technology is called "damper stopper." It should be noted that energy is not dissipated in the damper stoppers during seismic excitation.

Unique seismic response mitigation technologies have been used in cable-stayed bridges. The natural periods were shifted or adjusted by releasing the deck from towers so that base shear and flexural moment at the towers or deck displacement decrease. Used were various devices to shift the natural period and limit excessive deck displacement, such as links and elastic restrainers. Dampers were effectively used to mitigate the response.

The first attempt to develop a methodology of seismic isolation was realized in 1989 in the form of the "Guideline for Seismic Isolation of Highway Bridges" (Technology Research Center for Land Development 1989). Although it was not a mandate guideline, implementation of the seismic isolation to highway bridges was initiated in Japan at this time. Subsequently, a more comprehensive "Menshin Manual for Highway Bridges" was compiled in 1992 (Public Works Research Institute 1992, Kawashima 1992, Sugita and Mahin 1994). A consistent design procedure that takes account of response modification factors resulting from the hysteretic behavior of isolators and columns was 
developed. As will be described later, the minimum period shift was recommended in the Menshin Manual for Highway Bridges. It is called "Menshin Design."

The destructive damage of bridges and viaducts in the 1995 Kobe earthquake has led to a marked increase of seismic isolation. Many reinforced concrete or steel piers did not perform as well as might be expected under the strong excitation. It was recommended in the reconstruction of the damaged bridges that seismic isolation (Menshin Design) should be used, wherever possible, for multi-span continuous bridges (Ministry of Construction 1995). The design procedure proposed in the 1992 Menshin Manual was used. It was subsequently incorporated in the 1996 Design Specifications of Highway Bridges (Japan Road Association 1996, Kawashima and Unjoh 1997, Kawashima 2000). The lead rubber bearings (Robinson 1982) and the high damping rubber bearings have been increasingly adopted since the Kobe earthquake. Sliding bearing and buffer system (SBBS), consisting of PTFE sliding bearings and elastomeric buffers, has been developed as alternatives for the elastomeric isolators, and is also increasingly used in the recent application.

This paper introduces the current practice of seismic isolation of highway bridges, including design guidelines and implementation in Japan.

\section{PRINCIPLE OF SEISMIC ISOLATION}

\section{Performance Goals and Design Force}

Highway bridges with a span shorter than or equal to $200 \mathrm{~m}$ are designed according to the Design Specifications of Highway Bridges (Japan Road Association 2002). In the 2002 Design Specifications, there are four seismic performance goals depending on the levels and types of ground motions and the importance as shown in Table 1. For function-evaluation ground motions, both standard bridge and important bridges must behave in an elastic manner without any structural damage. For safety-evaluation ground motions, standard bridges should not collapse, while important bridges should perform with limited damage.

Table 1 Seismic performance criteria

\begin{tabular}{|c|c|c|c|}
\hline \multicolumn{2}{|c|}{ Ground Motions } & Standard Bridges & Important Bridges \\
\hline \multicolumn{2}{|c|}{ Function-Evaluation Ground Motions } & Functional & Functional \\
\hline Safety-Evaluation & Type-I (Middle-field GM) & Prevent Critical & Retain Limited \\
Ground Motions & Type-II (Near-field) & Damage & Damage \\
\hline
\end{tabular}

Function-evaluation response accelerations and safety-evaluation response accelerations for damping ratio $\xi=0.05$ are provided as follows:

Function-evaluation

$$
S=k_{Z} \cdot k_{D} \cdot \begin{cases}S_{1} \cdot T^{1 / 3} & \left(0<T \leq T_{1}\right) \\ S_{2} & \left(T_{1} \leq T \leq T_{2}\right) \\ S_{3} / T & \left(T_{2} \leq T\right)\end{cases}
$$

$\underline{\text { Safety-evaluation }}$

$$
S_{I}=k_{Z} \cdot k_{D} \cdot \begin{cases}S_{4} \cdot T^{1 / 3} & \left(0<T \leq T_{3}\right) \\ S_{5} & \left(T_{3} \leq T \leq T_{4}\right) \\ S_{6} / T & \left(T_{4} \leq T\right)\end{cases}
$$




$$
S_{I I}=k_{Z} \cdot k_{D} \cdot \begin{cases}S_{7} \cdot T^{2 / 3} & \left(0<T \leq T_{5}\right) \\ S_{8} & \left(T_{5} \leq T \leq T_{6}\right) \\ S_{9} / T^{5 / 3} & \left(T_{6} \leq T\right)\end{cases}
$$

in which $S_{i}(i=1-9)$ and $T_{i}(i=1-6)$ are shown in Table 2. $k_{Z}$ and $k_{D}$ represent the zone factor (1.0, 0.85 and 0.7 depending on the region and provided in a map) and damping modification factor, which is given by

$$
k_{D}=\frac{1.5}{40 \xi+1}+0.5
$$

in which $\xi$ is the damping ratio for 1st mode.

Table 2 Parameters in Eqs. (1)-(3) ( $T_{i}$ in second and $S_{i}$ in $\left.\mathrm{m} / \mathrm{s}^{2}\right)$

(a) Function-evaluation ground motion

\begin{tabular}{|c|c|c|c|c|c|}
\hline Soil Group & $\mathrm{T}_{1}$ & $\mathrm{~T}_{2}$ & $\mathrm{~S}_{1}$ & $\mathrm{~S}_{2}$ & $\mathrm{~S}_{3}$ \\
\hline I (Stiff) & 0.1 & 1.1 & 4.31 & 2.0 & 2.2 \\
\hline II (Moderate) & 0.2 & 1.3 & 4.27 & 2.5 & 3.25 \\
\hline III (Soft) & 0.34 & 1.5 & 4.3 & 3.0 & 4.5 \\
\hline
\end{tabular}

(b) Safety-evaluation ground motions

\begin{tabular}{|c|c|c|c|c|c|c|c|c|c|c|}
\hline \multirow{2}{*}{ Soil } & \multicolumn{4}{|c|}{ Type-I Ground Motion } & \multicolumn{5}{c|}{ Type-II Ground Motion } \\
\cline { 2 - 12 } Group & $\mathrm{T}_{3}$ & $\mathrm{~T}_{4}$ & $\mathrm{~S}_{4}$ & $\mathrm{~S}_{5}$ & $\mathrm{~S}_{6}$ & $\mathrm{~T}_{5}$ & $\mathrm{~T}_{6}$ & $\mathrm{~S}_{7}$ & $\mathrm{~S}_{8}$ & $\mathrm{~S}_{9}$ \\
\hline I (Stiff) & 0 & 1.4 & - & 7.0 & 9.8 & 0.3 & 0.7 & 44.63 & 20.0 & 11.04 \\
\hline II (Moderate) & 0.18 & 1.6 & 15.05 & 8.5 & 13.6 & 0.4 & 1.2 & 32.24 & 17.5 & 23.71 \\
\hline III (Soft) & 0.29 & 2.0 & 15.11 & 10.0 & 20.0 & 0.5 & 1.5 & 23.81 & 15.0 & 29.48 \\
\hline
\end{tabular}

Fig. 1 shows the response accelerations $S_{I}$ and $S_{I I}$ by Eqs. (2) and (3). Two-level design force with three response accelerations has been used after the Kobe earthquake. It should be noted that $S_{I}$ in Eq. (2) intends to represent the ground motions that were supposedly developed in Tokyo in the 1923 Kanto Earthquake (M7.9). Because of the large number of victims (about 140,000), the Kanto Earthquake has been regarded a special target for earthquake disaster mitigation. It was deterministically evaluated assuming a combination of $\mathrm{M}=8$ and epicenter distance $=50 \mathrm{~km}$ based on an attenuation equation of response acceleration developed from a statistical analysis of free-field ground motions. On the other hand, $S_{I I}$ in Eq. (3) was determined from the accelerations recorded in the 1995 Kobe earthquake $\left(M_{w}=7.3\right) . S_{I}$ and $S_{I I}$ are called Type-I and Type-II ground motions, respectively.

One of the unique points of the Japanese design force is that the elastic response accelerations used in the equivalent static analysis are modified taking account of the period-dependency of damping ratio of bridges. Based on forced excitation tests of bridges, an empirical relation was obtained for the small-amplitude period-dependent damping ratio as

$$
\xi \approx 0.02 / T
$$

Substituting Eq. (5) into Eqs. (1)-(3) through Eq. (4), the following elastic response accelerations for 


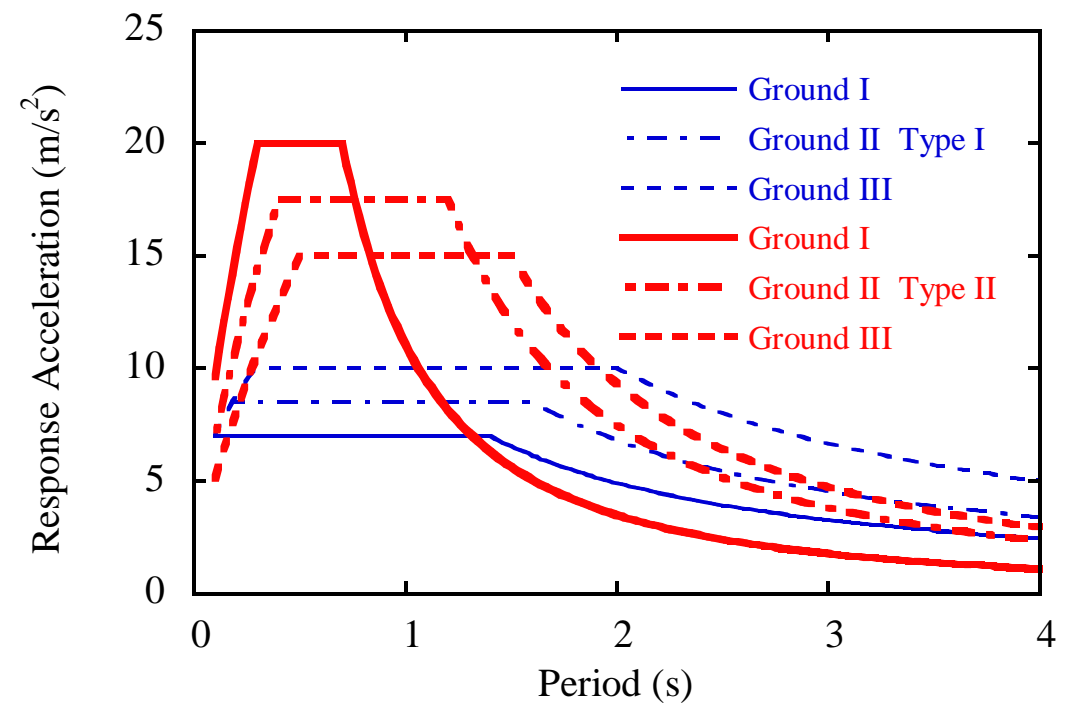

Fig. 1 Response Acceleration $S_{I}$ and $S_{I I}$ by Eqs.(2) and (3)

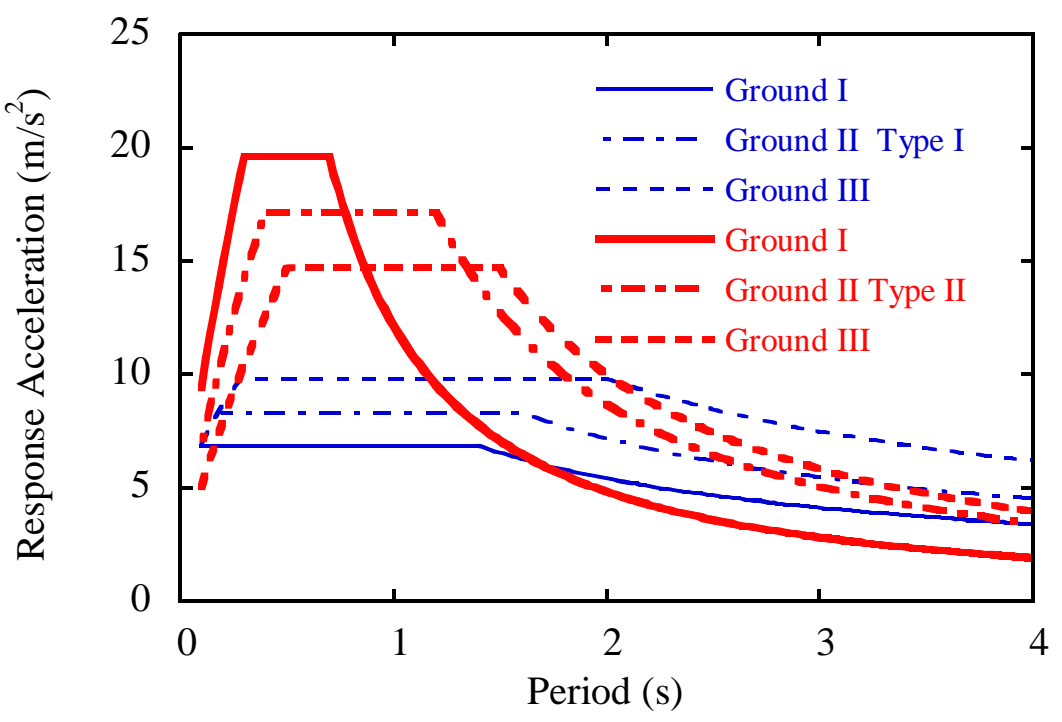

Fig.2 Response Acceleration $S_{S I}$ and $S_{S I I}$ by Eqs.(7) and (8)

the equivalent static analysis are obtained after some simplifications;

Function-evaluation

$\underline{\text { Safety-evaluation }}$

$$
S_{S}=k_{Z} \cdot \begin{cases}S_{S 1} \cdot T^{1 / 3} & \left(0<T \leq T_{1}\right) \\ S_{S 2} & \left(T_{1} \leq T \leq T_{2}\right) \\ S_{S 3} / T^{2 / 3} & \left(T_{2} \leq T\right)\end{cases}
$$

$$
S_{S I}=k_{Z} \cdot \begin{cases}S_{S 4} \cdot T^{1 / 3} & \left(0<T \leq T_{3}\right) \\ S_{S 5} & \left(T_{3} \leq T \leq T_{4}\right) \\ S_{S 6} / T^{2 / 3} & \left(T_{4} \leq T\right)\end{cases}
$$




$$
S_{S I I}=k_{Z} \cdot \begin{cases}S_{S 7} \cdot T^{2 / 3} & \left(0<T \leq T_{5}\right) \\ S_{S 8} & \left(T_{5} \leq T \leq T_{6}\right) \\ S_{S 9} / T^{4 / 3} & \left(T_{6} \leq T\right)\end{cases}
$$

in which $S_{S i}(i-1-9)$ are given in Table 3, and $T_{i}$ (i=1-6) are the same periods in Eqs. (1)-(3). Fig. 2 shows the response accelerations $S_{S I}$ and $S_{S I I}$ by Eqs. (7) and (8).

Table 3 Parameters in Eqs. (6)-(8) in $\mathrm{m} / \mathrm{s}^{2}$

\begin{tabular}{|c|c|c|c|c|c|c|c|c|c|}
\hline \multirow{2}{*}{$\begin{array}{c}\text { Soil } \\
\text { Group }\end{array}$} & \multicolumn{3}{|c|}{ Function-Evaluation } & \multicolumn{6}{|c|}{ Safety-Evaluation } \\
\cline { 2 - 10 } & & & \multicolumn{3}{|c|}{ Type-I Ground Motion } & \multicolumn{2}{c|}{ Type-II Ground Motion } \\
\hline & $S_{S 1}$ & $S_{S 2}$ & $S_{S 3}$ & $S_{S 4}$ & $S_{S 5}$ & $S_{S 6}$ & $S_{S 7}$ & $S_{S 8}$ & $S_{S 9}$ \\
\hline I & 4.22 & 1.96 & 2.09 & - & 6.86 & 8.58 & 43.7 & 19.6 & 12.15 \\
\hline II & 4.18 & 2.45 & 2.92 & 14.8 & 8.33 & 11.37 & 31.8 & 17.15 & 21.85 \\
\hline III & 4.21 & 2.94 & 3.85 & 14.8 & 9.8 & 15.58 & 23.3 & 14.7 & 25.2 \\
\hline
\end{tabular}

\section{Basic Principle of Seismic Isolation}

The period shift and the enhancement of energy dissipation capacity are the basic principles of seismic isolation (Skinner, Robinson and McVerry, 1993). However the natural period of a bridge has to be carefully evaluated, since the period shift generally brings an increase of response displacement in a deck. For example, a 10m-high standard urban highway viaduct with a fixed-base natural period of about 0.8 second may have the natural period of 1.5-2 seconds when isolated, and response displacement of the deck may be in the range of 0.3-0.7 $\mathrm{m}$ when the bridge is subjected to the ground motions by Eqs. (2) and (3). Relative displacement between viaducts may be further amplified due to the phase delay.

Since the clearance between decks at an expansion joint is generally $0.1-0.3 \mathrm{~m}$ in a standard bridge, the decks cannot displace as expected in a design earthquake, which results in insufficient period shift and energy dissipation. Furthermore, such a large relative displacement would result in collisions between decks, which, in turn, causes excessive large lateral force to transfer from one deck to the other. It should be noted that expansion joints that accommodate large relative displacement is not desirable, because it causes vibration and noise problems as well as overwhelming maintenance in an urban area.

Hence in the application of seismic isolation to bridges and viaducts, it has been recommended that the natural period should not be excessively increased but that an emphasis should be placed for the increase of energy dissipation capacity and the distribution of seismic lateral force of a deck to as many piers as possible. The natural period of an isolated bridge has been recommended about twice the natural period of the fixed-base bridge. As described earlier, such a design practice has been called "Menshin Design." It should be noted that inelastic hysteretic response might occur in piers in the Menshin Design because of the limited period shift. The Menshin Design has been used as a design tool that enables to construct multi-span continuous bridges with the distribution of seismic lateral force to piers.

\section{DESIGN}

\section{System Design}

An isolated bridge is sized by the elastic static analysis for the function-evaluation ground motions, 
followed by the inelastic static analysis for the safety-evaluation ground motions. Subsequently, an elastic and inelastic dynamic response analysis is conducted to verify the seismic performance of a bridge system.

In the nonlinear static analysis, the equivalent lateral force $F_{e q}$ is evaluated based on the response modification factor $R_{E}$ that stands on the energy dissipation in dampers, and the response modification factor $R_{\mu}$ that stands on the inelastic response of piers as

where,

$$
F_{e q}=\frac{F}{R_{E} \cdot R_{\mu}}
$$

$$
\begin{gathered}
F=S_{S I} \cdot W / g \text { or } F=S_{S I I} \cdot W / g \\
R_{\mu}=\sqrt{2 \mu_{m}-1}
\end{gathered}
$$

in which $F$ : elastic lateral force, $S_{S I}$ and $S_{S I I}$ : type-I and type-II elastic response accelerations in the equivalent static analysis by Eqs. (7) and (8), $W$ : tributary weight, and $\mu_{m}$ : design ductility capacity of a pier. The response modification factor $R_{E}$ is provided as shown in Table 4 depending on the first-mode damping ratio of a bridge $\xi$. It should be noted that the response modification factor $R_{\mu}$ is 1.0 in design of a fixed-base bridge.

Table 4 Response modification factor depending on energy dissipation capacity $R_{E}$

\begin{tabular}{|c|c|}
\hline $\begin{array}{c}\text { First-mode } \\
\text { Damping Ratio } \xi\end{array}$ & $\begin{array}{c}\text { Response Modification } \\
\text { Factor } R_{E}\end{array}$ \\
\hline$\xi<0.1$ & 1.0 \\
\hline $0.1 \leq \xi<0.12$ & 1.11 \\
\hline $0.12 \leq \xi<0.15$ & 1.25 \\
\hline $0.15 \leq \xi$ & 1.43 \\
\hline
\end{tabular}

In a fixed-based bridge, the design ductility capacity of a pier $\mu$ is given by

$$
\mu=1+\frac{u_{u}-u_{y}}{\alpha \cdot u_{y}}
$$

in which $u_{y}$ and $u_{u}$ : yield and ultimate displacements, respectively, of a pier, and $\alpha$ : safety factor.

The yield and ultimate displacements are evaluated at each pier based on the fiber element analysis. The safety factor $\alpha$ depends on the importance of a bridge and the ground motions as shown in Table 5. On the other hand, the design ductility factor $\mu_{m}$ in Eq. (11) is evaluated by

$$
\mu_{m}=1+\frac{u_{u}-u_{y}}{\alpha_{m} \cdot u_{y}}
$$

in which $\alpha_{m}$ is safety factor for an isolated bridge, and is given as 


$$
\alpha_{m}=2 \alpha
$$

If $\mu$ by Eq. (12) or $\mu_{m}$ by Eq. (13) is lager than 8, it should be 8. Consequently, the response modification factor $R_{\mu}$ by Eq. (11) should not be larger than 3.8.

Table 5 Safety factor $\alpha$ in Eq. (12)

\begin{tabular}{|c|c|c|}
\hline Importance & Type-I GM & Type-II GM \\
\hline Standard Bridges & 3.0 & 1.5 \\
\hline Important Bridges & 2.4 & 1.2 \\
\hline
\end{tabular}

The first-mode damping ratio $\xi$ in Table 4 has to be carefully evaluated. A method to evaluate $\xi$ by taking average of damping ratios of each structural segment is presented in the Design Specifications of Highway Bridges. A bridge may be divided into several structural segments in which energy dissipation mechanism is essentially the same. If one specifies a damping ratio at each structural segment for the first mode, the first-mode damping ratio $\xi$ may be obtained as

$$
\xi=\frac{\sum \xi_{k} \cdot \phi_{k}^{T} \cdot k_{k} \cdot \phi_{k}}{\sum \phi_{k}^{T} \cdot k_{k} \cdot \phi_{k}}
$$

in which $\xi_{k}$ : first-mode damping ratio of k-th structural segment, $\phi_{i}$ : first-mode vector, and $k_{k}$ : stiffness matrix of k-th structural segment. Table 6 shows first-mode damping ratios $\xi_{k}$ for major structural segments recommended to be used in the equivalent-linearlized analysis. It should be noted that when the hysteretic energy dissipation is included in an anlysis using nonlinear elements, it's effect has to be eliminated from the damping ratio presented in Table 6. For example, 0.01 and 0.02 are recommended for the damping ratio of reinforced concrete members and steel members, respectively, when the hysteretic behavior is taken into account in an analysis using nonlinear elements.

Table 6 Recommended first-mode damping ratios

\begin{tabular}{|c|c|c|c|c|}
\hline \multirow{2}{*}{ Structural Segments } & \multicolumn{2}{|c|}{ Elastic Response } & \multicolumn{2}{c|}{ Inelastic Response } \\
\cline { 2 - 5 } & Steel & Concrete & Steel & Concrete \\
\hline Deck & $0.02-0.03$ & $0.03-0.05$ & $0.02-0.03$ & $0.03-0.05$ \\
\hline Elastomeric Bearings & \multicolumn{2}{|c|}{0.02} & \multicolumn{2}{c|}{0.02} \\
\hline Isolation Bearings & \multicolumn{2}{|c|}{$\begin{array}{c}\text { Equivalent Damping } \\
\text { Ratio by Eq. (18) }\end{array}$} & $\begin{array}{c}\text { Equivalent Damping } \\
\text { Ratio by Eq. (18) }\end{array}$ \\
\hline Piers & $0.03-0.05$ & $0.05-0.1$ & $0.1-0.2$ & $0.12-0.2$ \\
\hline Foundations & \multicolumn{2}{|c|}{$0.1-0.3$} & \multicolumn{2}{c|}{$0.2-0.4$} \\
\hline
\end{tabular}

\section{Design of Devices}

Isolators and energy dissipaters have to be stable to design ground motions, and they should be replaceable when damaged. They are designed for a target design displacement $u_{B}$ as

$$
u_{B}=\frac{F_{e q}}{K_{B}}
$$


in which $F_{e q}$ is the equivalent lateral force in the inelastic static analysis by Eq. (9), and $K_{B}$ is the equivalent stiffness of a device. The equivalent stiffness $K_{B}$ and the equivalent damping ratio $\xi_{B}$ of a device are defined by

$$
\begin{gathered}
K_{B}=\frac{F_{B}\left(u_{B e}\right)-F\left(-u_{B e}\right)}{2 u_{B e}} \\
\xi_{B}=\frac{\Delta W}{2 \pi W}
\end{gathered}
$$

where,

$$
u_{B e}=c_{B} \cdot u_{B}
$$

in which $F_{B}(u)$ : restoring force of a device at displacement of $u, u_{B e}$ : equivalent displacement, $c_{B}$ : coefficient to evaluate the effective displacement (=0.7), $\Delta W$ : energy dissipation of a device per cycle, and $W$ : elastic strain energy.

In design of devices, the following requirements have to be satisfied:

- Displacement of a devise computed by Eq. (16) should be within $+/-10 \%$ from the assumed design displacement $u_{B}$, and the equivalent damping ratio evaluated by Eq. (18) should not be less than the equivalent damping ratio assumed in design.

- Shear strain in an elastomeric bearing $\gamma_{B}$ subjected to the equivalent lateral force $F_{e q}$ defined by

$$
\lambda_{B} \equiv \frac{u_{B}}{\sum_{r=1}^{n} t_{r i}}
$$

should be less than $250 \%$, in which $u_{B}$ is the design displacement by Eq. (16), $t_{r i}$ is the thickness of $i$-th rubber layer, and $n$ is the number of rubber layers.

- Local shear strain should be less than the rupture strain divided by a factor of 1.2.

- Devices have to be designed and fabricated so that scatter of the equivalent stiffness $K_{B}$ and the equivalent damping ratio $\xi_{B}$ are within $10 \%$ of the design values.

- Devices have to be stable for at least 50 and 15 lateral load reversals with the design displacements $u_{B}$ by Eq. (16) for the Type-I and Type-II ground motions, respectively, under a vertical static load equivalent to the tributary weight.

- To prevent "shake-down," tangential stiffness of a device should be positive at any displacement within the design displacement $u_{B}$.

- A deck should return to the rest position after it is subjected to design ground motions. Residual displacement $u_{B R}$ developed in a device after it is smoothly released from a deformed displacement equivalent to the design displacements $u_{B}$ should be less than $10 \%$ of the design displacement.

- The equivalent stiffness $K_{B}$ and the equivalent damping ratio $\xi_{B}$ should be stable for a change of load conditions and natural environment including the thermal extension of a deck.

\section{TYPICAL APPLICATIONS OF SEISMIC ISOLATION}

\section{Application to a 29-span Continuous Viaduct}


O-Hito Viaduct is a $1.929 \mathrm{~km}$ long 66-span viaduct as shown in Photo 1. It is a part of National Highway 135 in Izu Peninsula. It is separated into 5 segments (7, 29, 15, 3 and 12 span continuous viaducts). Application of the seismic isolation is presented here for a $725 \mathrm{~m}$ long 29 -span continuous viaduct. A reinforced concrete hollow slab deck with a $29 \mathrm{~m}$ long span $(25 \mathrm{~m} \times 29$-span $=725 \mathrm{~m})$ is supported by 4 lead rubber bearings per pier. The size of lead-rubber bearings was $580 \mathrm{~mm} \times 580 \mathrm{~mm}$ at the end piers (refer to Photo 2) and $680 \mathrm{~mm} \times 680 \mathrm{~mm}$ at the intermediate piers. $7.5 \mathrm{~m}$ tall reinforced concrete piers support the deck as shown in Photo 3.

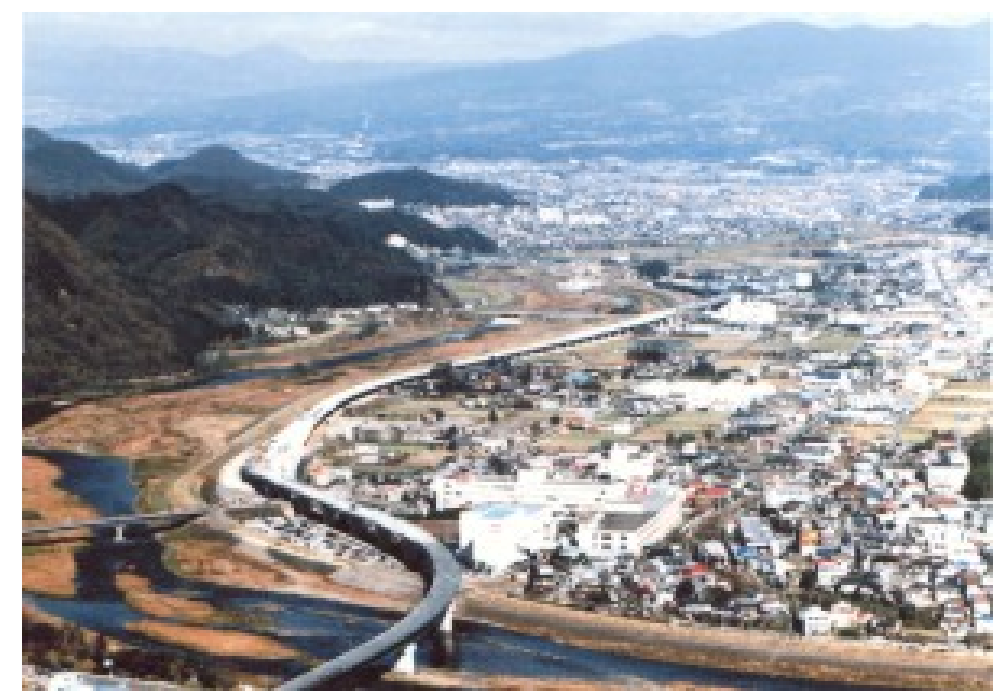

Photo 1 Ohito viaduct

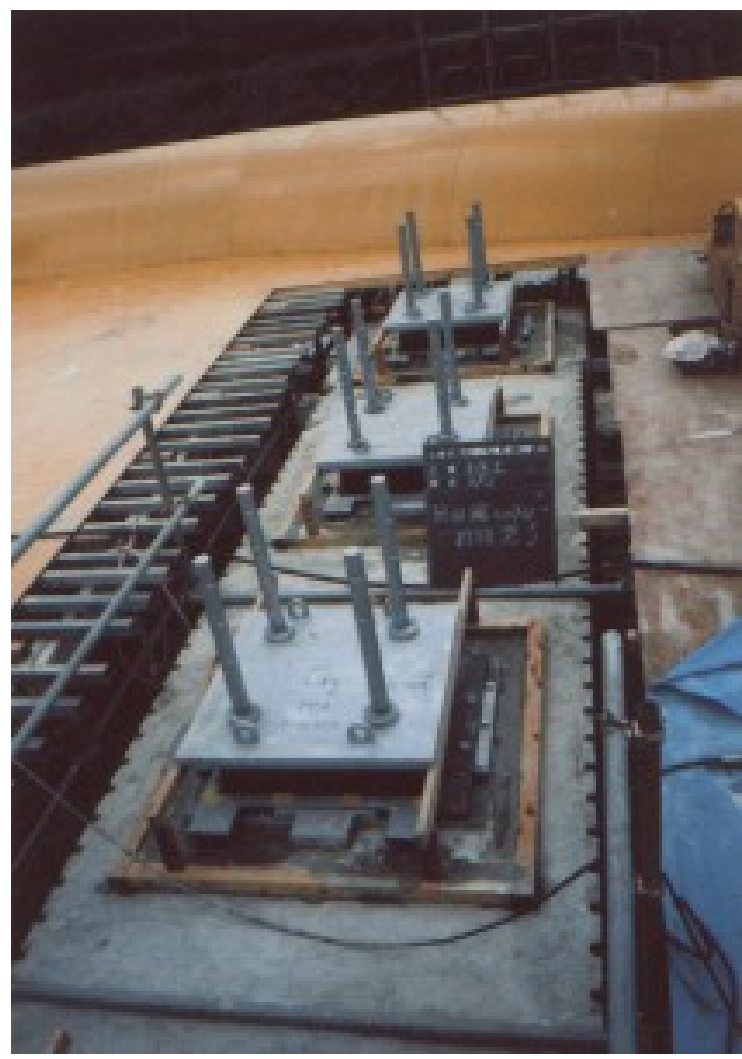

Photo 2 Lead rubber bearings, Ohito viaduct 


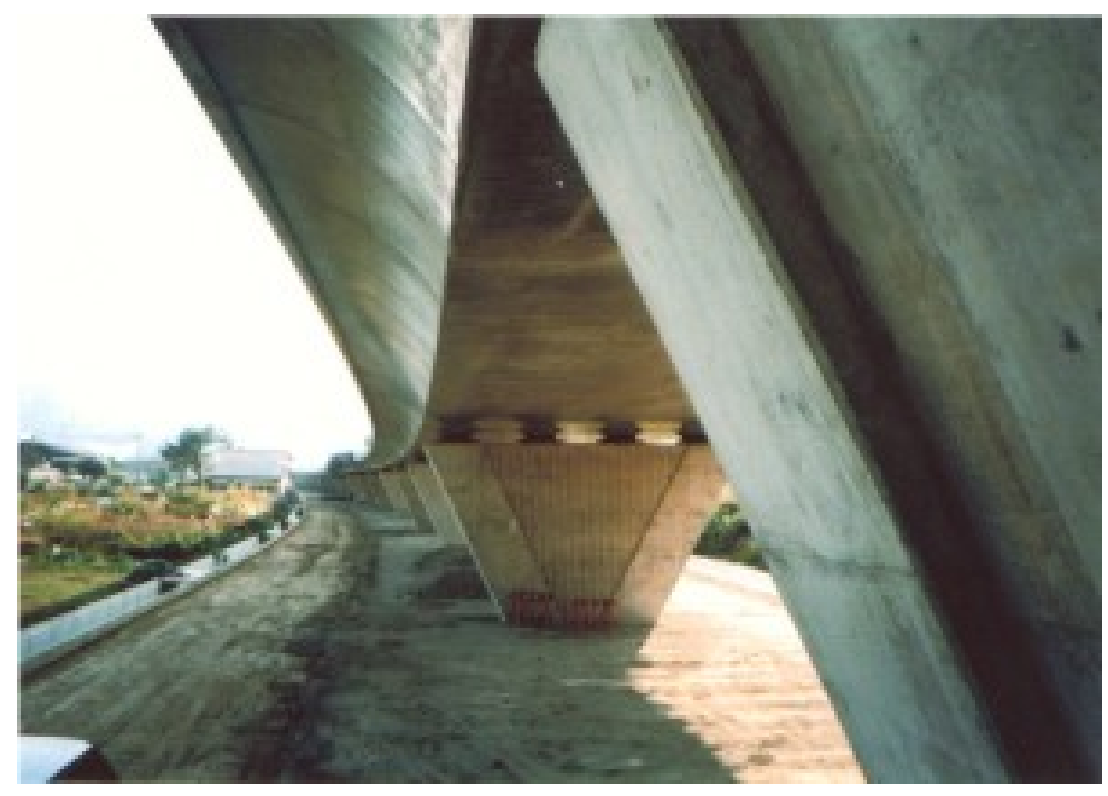

Photo 3 Ohito viaduct

Since the expected deck displacement resulting from the thermal effect and the creep plus shrinkage of concrete was about $70 \mathrm{~mm}$ and $130 \mathrm{~mm}$, respectively, repositioning of bearing after the initial setting was required. Consequently, a device was provided between a lower plate of LRB and a base plate as shown in Photo 4 so that flat jacks can reposition the lower plate of LRB.

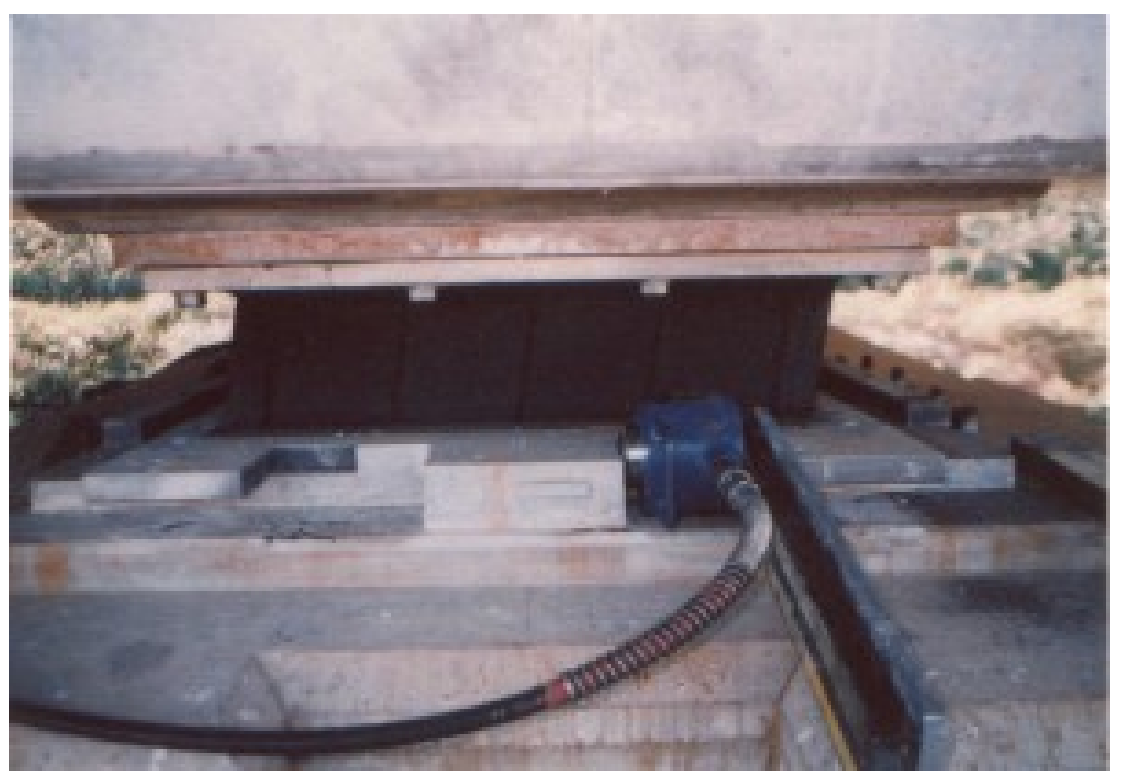

Photo 4 Repositioning of lower plate, Ohito viaduct

\section{Implementation of Sliding Bearings and Buffers System}

In the elastomeric-type isolations such as the lead rubber bearings and the high-damping rubber bearings, the laminated rubber resists the seismic lateral force under the vertical load corresponding to dead weight of a superstructure and traffic load. Although it is beneficial in those devices to be compact, the thickness of laminated rubber that is required to accommodate relative displacement as a 
consequence of the seismic, thermal, creep and shrinkage effects increases as the total deck length increases.

Consequently, a combination of high-pressure PTFE sliding bearings and laminated rubber buffers as shown in Fig. 3 is increasingly used for seismic isolation of long multi-span continuous bridges. This is called "sliding bearing and buffer system (SBBS)." Use of PTFE sliding bearings brings a benefit that the bearings are thinner than the normal elastomeric bearings. Since the buffers are free from the support of the dead weight of a deck, the natural period is more easily controlled than is the case with the normal elastomeric-type isolators. Consequently the system is beneficial for viaducts that sustain larger relative displacement resulting from the seismic, thermal, creep and shrinkage effects.

Photos 5 and 6 show Wakayama Bypath, Ministry of Land, Infrastructure and Transport that uses the SBBS system. It is a $301.5 \mathrm{~m}$ long 12-span continuous hollow reinforced concrete slab bridge supported by $8.3-8.6 \mathrm{~m}$ tall reinforced concrete piers. The deck was supported by two PTFE sliding bearings per pier. Two elastomeric buffers were installed per pier between a reinforced concrete block connected to the deck and two reinforced concrete blocks connected to the pier. By adopting the SBBS system, the cost of bearings decreased by about 30\% from the original design using elastomeric bearings. It resulted in $6 \%$ cost reduction for a superstructure and bearings.

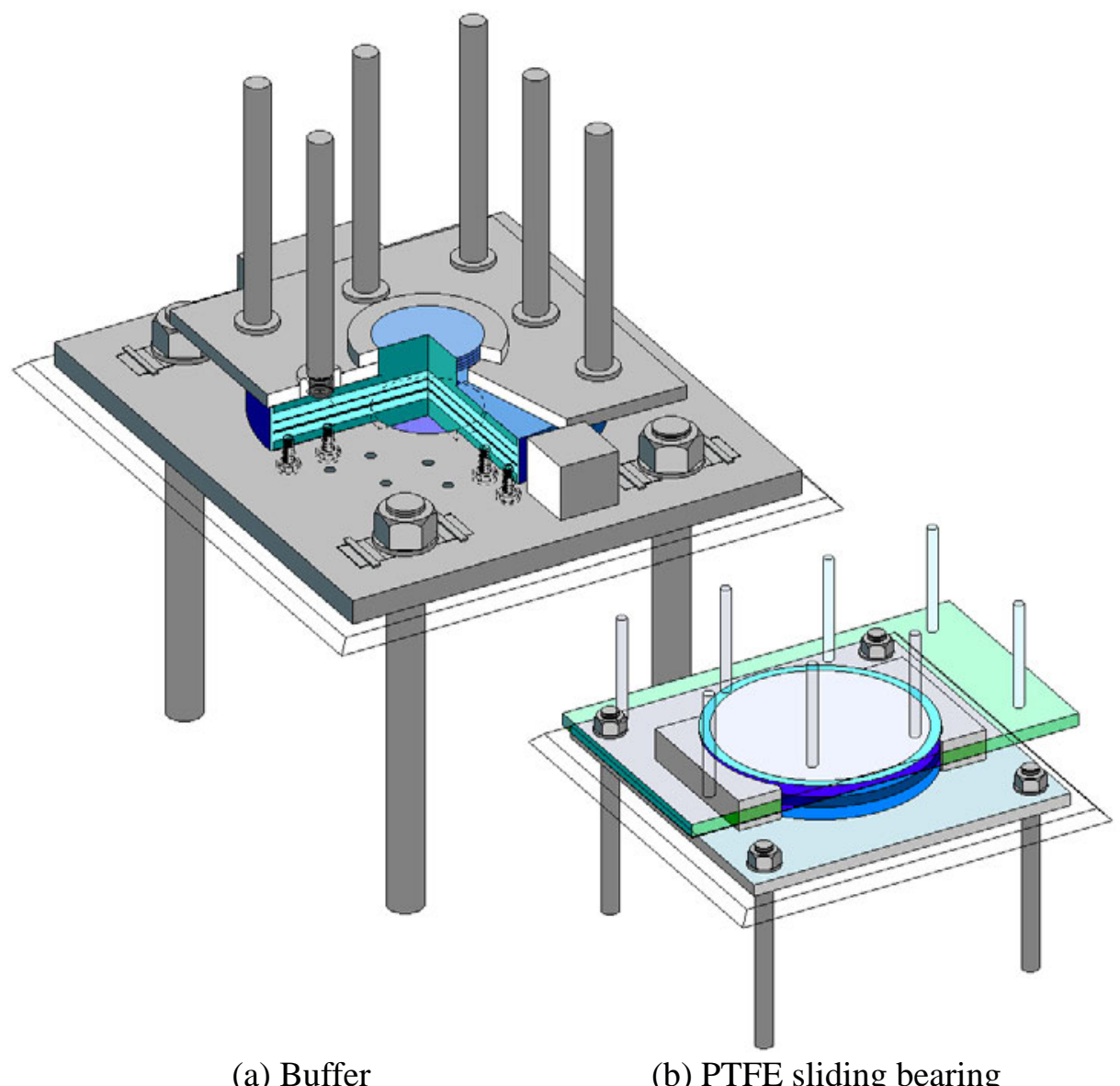

(a) Buffer

(b) PTFE sliding bearing

Fig. 3 Sliding bearing and buffer system (SBBS) 


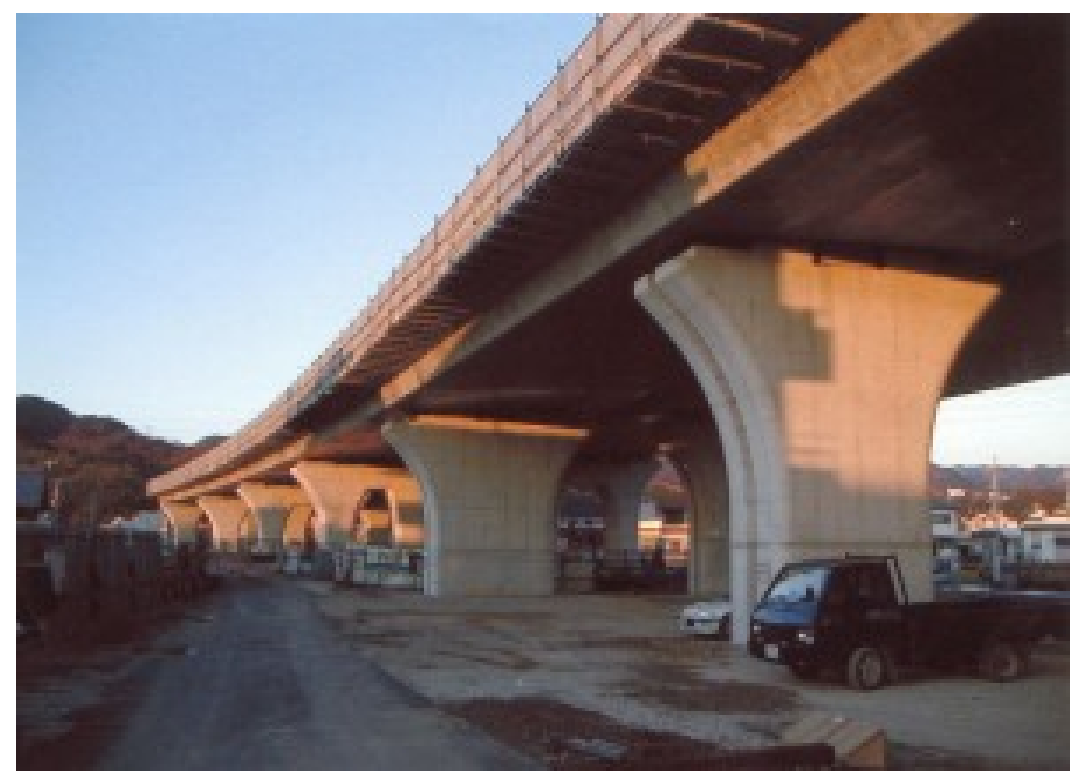

Photo 5 Wakayama bypath viaduct

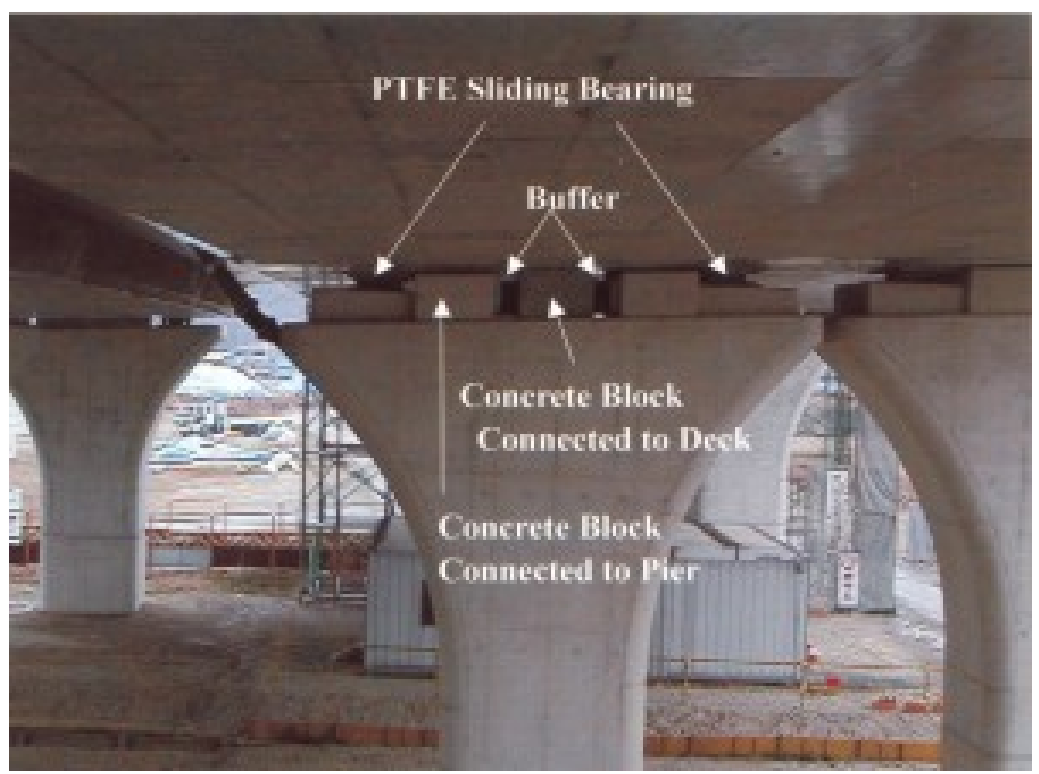

Photo 6 Sliding bearing and buffer system (SBBS), Wakayama bypath viaduct

\section{Implementation to Reconstruction of a 18-span Continuous Viaduct}

An 18-span reinforced concrete continuous bridge at Fukae, Route 3, Hanshin Expressway, collapsed as shown in Photo 7 during the 1995 Kobe earthquake. The damage occurred resulting from premature shear failure of reinforced concrete piers. After the earthquake, the damaged superstructure and the 17 piers were demolished. Since the 17 pile foundations suffered minor damage, a design strategy that enabled to re-use the foundations was sought for minimizing the reconstruction period. Consequently it was decided to construct two 8-span continuous steel box girder bridges using 19 of the 20 existing pile foundations. 


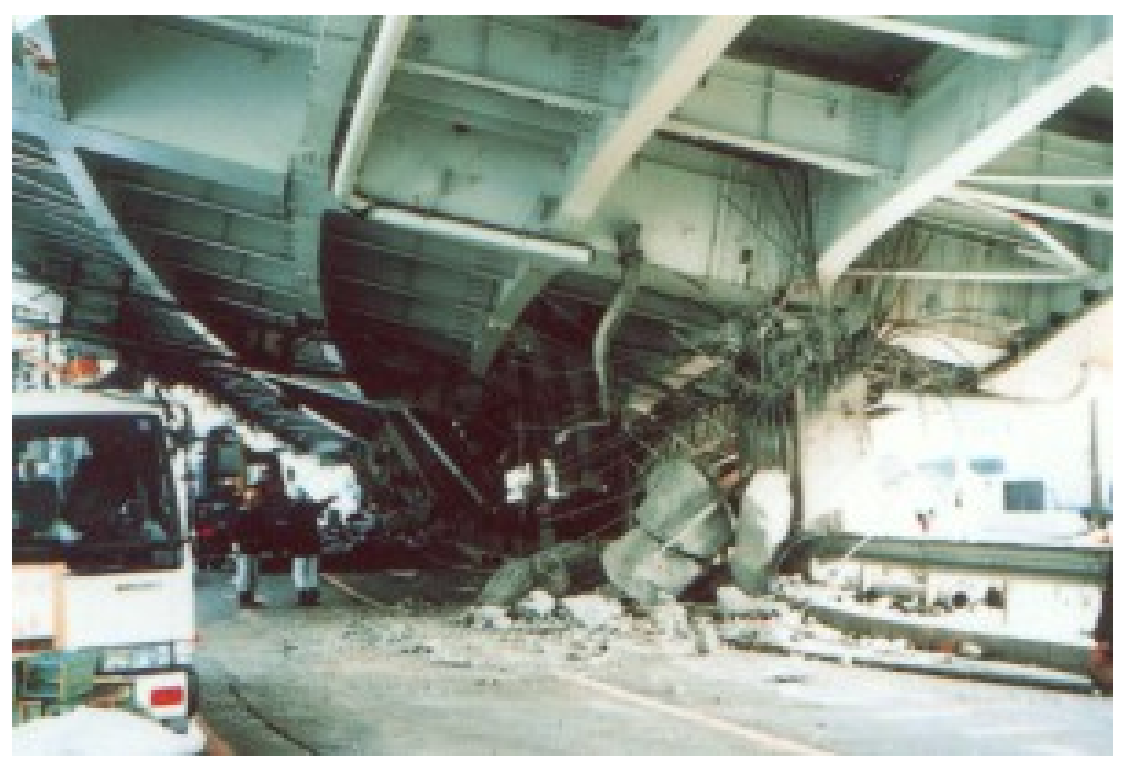

Photo 7 Collapse of Benten viaduct, Route 3, Hanshin Expressway, in the 1995 Kobe earthquake

Seismic isolation was adopted to reduce the lateral force so that the existing foundations were re-used. A unique point in the application of seismic isolation was that the lead rubber bearings were placed between the bottoms of framed steel piers and the footing as shown in Photo 8. It led to the decrease of bending moment in the pile foundations. For the same purpose, steel deck replaced the original reinforced concrete decks. Photo 9 shows the Benten Viaduct after reconstruction.

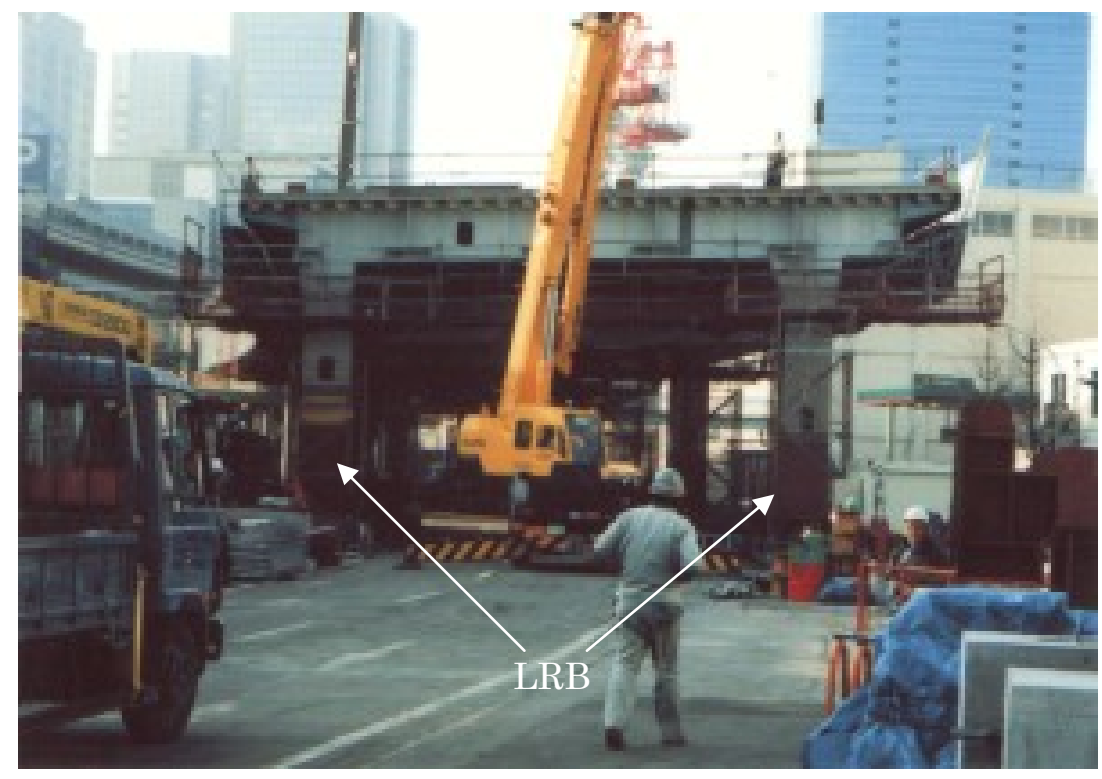

Photo 8 Lead rubber bearings installed under the bottoms of a steel frame 


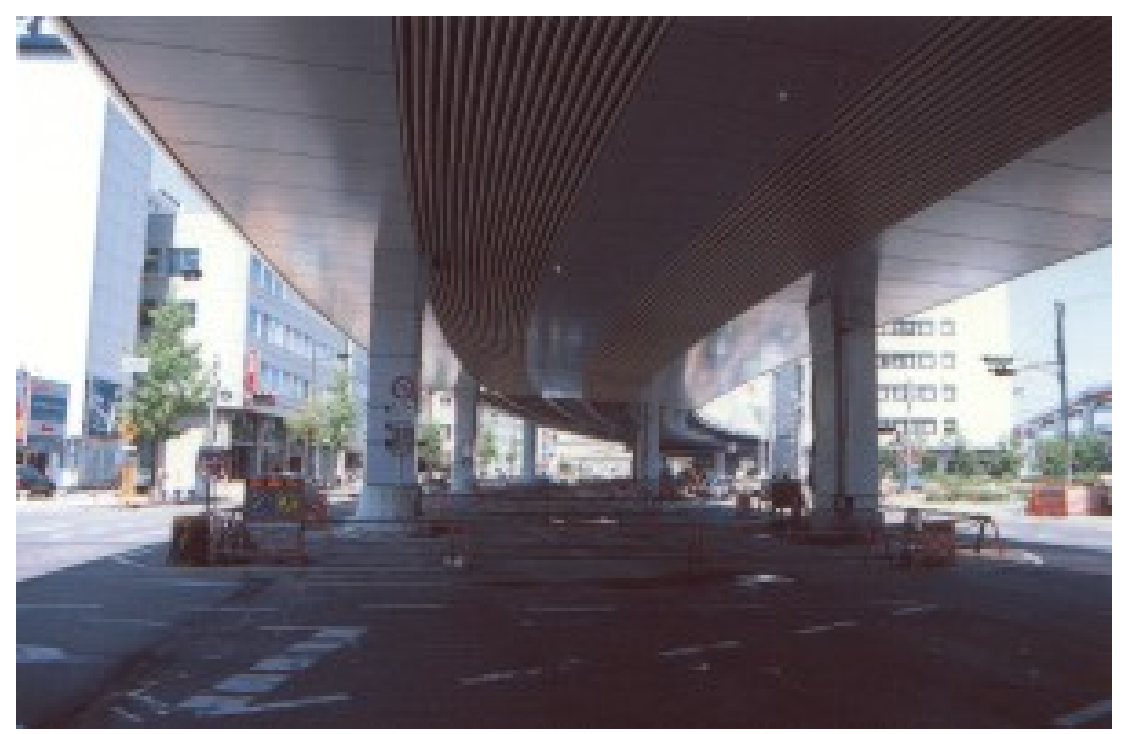

Photo 9 Benten viaduct after reconstruction

\section{CONCLUSIONS}

Three recent examples of application of seismic isolation (Menshin design) to bridges were introduced as well as the design guidelines. Significant technical developments contributed the construction of isolated bridges. About 1,500-2,000 bridges have been constructed annually in the last 10 years in Japan. While most bridges used steel bearings prior to the 1995 Kobe earthquake, the elastomeric bearings have been extensively used after the Kobe earthquake. Extensive damage of steel bearings revealed the fact that steel bearings are vulnerable under an extensive ground motion. Lead rubber bearings and high damping rubber bearings are widely used as a part of the elastomeric bearings. New devices such as the High Performance Stopper and Buffer System are being implemented.

As well as the enhancement of seismic performance of a bridge under an extensive ground motion, the distribution of deck seismic lateral force is the main concern of owners and designers in the use of elastomeric bearings in a multi-span continuous bridge. Designers are reluctant to reduce the seismic lateral force depending on the force reduction factor associated with the energy dissipation by isolators and dampers $R_{E}$ in Eq. (9). Consequently $R_{E}$ is often disregarded in the implementation of seismic isolation. Verification of the seismic performance of bridges under extreme earthquakes is required for the more active implementation of seismic isolation.

\section{ACKNOWLEDGMENTS}

The author wishes to thank a number of members and organizations for providing him with valuable information. Special appreciation is extended to Dr. Adachi, Y., Hanshin Expressway Public Corporation, Dr. Unjoh, S., Public Works Research Institute, Ms. Iiyama, K. and Mr. Hirose, A., Chuo-Fukken Consultants, Mr. Yamashita, M., Kaihatsu Consultants, Messrs. Goda, Y. and Haino, H., BBM, Messrs. Uruta H. and Sudo, C., Bridgestone, and Messrs. Honma, Y., Hasegawa, K., Shimanoe, S. and Koshitoge, M., Yokohama Rubber.

\section{REFERENCES}

Japan Road Association (1964, 1980, 1990, 1996, 2002). "Design specifications of highway 
bridges.” Maruzen, Tokyo, Japan

Kawashima, K. (1992). "A perspective of Menshin design for highway bridges.” Proc. 1st US-Japan Workshop on Earthquake Protective Systems for Bridges, 3-26, Technical Report NCEER 92-4, National Center for Earthquake Engineering Research, State University of New York, Buffalo, NY, USA

Kawashima, K. and Unjoh, S. (1997). "The damage of highway bridges in the 1995 Hyogo-ken nanbu earthquake and its impact on Japanese seismic design.” Journal of Earthquake Engineering, Vol. 1, No. 3, 505-541.

Kawashima, K. (2000). "Seismic design and retrofit of bridges.” Key Note Presentation, 12th World Conference on Earthquake Engineering, Paper No. 1818 (CD-ROM), Auckland, New Zealand

Ministry of Construction (1995). "Guide specifications for reconstruction and repair of highway bridges which suffered damage in the Kobe earthquake.” (in Japanese)

Public Works Research Institute (1992). "Menshin manual of highway bridges.” Tsukuba, Japan.(in Japanese)

Robinson, W. H. (1982). "Lead-rubber hysteretic bearing suitable for protecting structures during earthquakes,” Earthquake Engineering and Structural Dynamics, Vol. 10, 593-604.

Skinner, R. V., Robinson, W. H. and McVerry, G. H. (1994). "An introduction to seismic isolation.” John Wiley \& Sons, New York, USA

Sugita, H. and Mahin, S. (1994). "Manual for Menshin design of highway bridges: Ministry of Construction, Japan.” Report No. UCB/EERC 94-10, Earthquake Engineering Research Center, University of California, Berkeley, CA, USA.

Technology Research Center for Land Development (1989). "Guideline for seismic isolation of highway bridges.” Tokyo, Japan (in Japanese) 